\title{
CARACTERIZAÇÃO MAGNÉTICA PRÉ E PÓS DEFORMAÇÃO DE AÇOS DE CONSTRUÇÃO NÃO LIGADOS ATRAVÉS DA TÉCNICA BITTER (FERROFLUIDO)*
}

Lucas Kling e Silva ${ }^{1}$ Nadja Sonntag ${ }^{2}$ Birgit Skrotzki $i^{3}$

\section{Resumo}

A deformação plástica de aços acompanha mudanças irreversíveis da microestrutura, que podem ser consideradas como o estágio inicial do processo de fratura. No entanto, detectar, monitorar e avaliar previamente, estados de dano e pequenos defeitos, de forma não destrutiva, ainda se mostra desafiador. Dubov reportou o fenômeno do surgimento espontâneo de fracos campos magnéticos em aços estruturais ferríticos em oleodutos, que são originados devido a tensões mecânicas heterogêneas ou térmicas. Esta observação não é associada com transformações de fase induzidas por deformação e parece ser uma ferramenta promissora para a caracterização prévia de danos em aços ferromagnéticos. Para proporcionar uma melhor compreensão das bases físicas deste processo, foram observadas as microestruturas magnéticas de tais materiais e as mudanças ocorridas nos domínios magnéticos dos mesmos após sofrerem deformação plástica. Para isto foi utilizado um meio de solução coloidal com partículas paramagnéticas na escala nanométrica (ferrofluido) que proporcionou, através da técnica Bitter, observar não apenas uma mudança de tamanho dos domínios magnéticos do material, mas também modificações em sua morfologia. Foram estudados neste trabalho aços ferríticos com as respectivas concentrações de carbono em sua composição: $0,12 \% ; 0,17 \%$ e $0,45 \%$.

Palavras-chave: Domínios magnéticos; Técnica Bitter; Aços; Ferrofluido.

\section{MAGNETIC CHARACTERIZATION BEFORE AND AFTER DEFORMATION OF NON-ALLOYED CONTRUCTION STEELS USING BITTER TECHNIC}

\section{Abstract}

The plastic deformation results in irreversible microstructure changes in the steel, which can be considered as the initial stage of the fracture process. However, detecting, monitoring and evaluating, damage states and small defects nondestructively in advance still proves challenging. Dubov reported the phenomenon of the spontaneous emergence of weak magnetic fields in ferritic structural steel and pipelines, which originate due to heterogeneous mechanical and / or thermal stresses. This observation is not associated with induced phase transformations by deformation and appears to be a promising tool for the prior characterization of damage in ferromagnetic steels. To provide a better understanding of the physical bases of the process, the magnetic microstructure of such materials and a change of magnetic domains after undergoing plastic deformation were studied. A colloidal solution with paramagnetic particles in the nanometer range (ferrofluid), which allowed, through the Bitter technique, not only to observe a change in size of the magnetic domains of the material, but also changes in their morphology. Ferritic steels with their concentrations of carbon in its composition $(0.12 \% ; 0.17 \%$ and $0.45 \%)$ were studied in this work.

Keywords: Magnetic domains; Bitter technique; Steels; Ferrofluid.

1 Graduando em Engenharia Metalúrgica, Departamento de Engenharia Metalúrgica e Materiais, Universidade federal do Rio de Janeiro - UFRJ, Rio de Janeiro, Rio de Janeiro, Brasil.

2 Doutoranda em Engenharia de Materiais, Mestra, pesquisadora, Fachbereich 5.2 Experimentelle und modellbasierte Werkstoffmechanik, Bundesanstalt für Materialforschung und -prüfung, Berlin, Alemanha.

3 Doutora em Engenharia de Materiais, Professora Doutoura Engenheira, Chefe de departamento, Fachbereich 5.2 Experimentelle und modellbasierte Werkstoffmechanik, Bundesanstalt für Materialforschung und -prüfung, Berlin, Alemanha. 


\section{INTRODUÇÃO}

Dubov relatou o surgimento espontâneo de fracos campos magnéticos em aços ferríticos após estes serem submetidos a deformações plásticas. Tais campos emergem não devido a alterações de fases microestruturais induzidas mecanicamente ou termicamente, mas sim por interações magneto-mecânicas [1]. 0 surgimento destes campos magnéticos e a influência do efeito de topografia proveniente da deformação plástica foram estudados de forma a revelar que sua intensidade provém além de mudanças topográficas [2]. Para uma melhor compreensão do mecanismo físico deste processo de magnetização nos materiais ferríticos após deformações plásticas são necessárias pesquisas magneto-óticas.

Acredita-se que este processo de magnetização se dá devido a alterações da orientação dos domínios magnéticos destes materiais. Para que isto possa ser observado foi utilizada a técnica Bitter através de ferrofluido. Assim sendo, foi feito um estudo com o intuído de observar como se mostram os domínios magnéticos nos aços em questão, antes e após deformação plástica, e como esta microestrutura magnética se relaciona com a microestrutura convencional destes mesmos aços. Neste trabalho serão apresentados resultados do aço St37 após deformação, que se mostra representativo quanto a outros resultados obtidos.

\subsection{Domínios Magnéticos}

Quando os aços ferromagnéticos são resfriados abaixo da temperatura de Curie ocorre o alinhamento dos spins de seus elétrons, o que gera polos magnéticos eletroestáticos. Esse alto estado energético não é favorável, então surgem regiões de forma homogênea e espontânea por todo o material com spins direcionados em direções distintas de modo a anularem uns aos outros quando somados de forma geral. Estas regiões são chamadas de domínios magnéticos e garantem um estado de energia favorável [3]. Um exemplo pode ser observado na figura 1.

Domínios magnéticos são áreas separadas entre si as quais os sentidos de magnetização giram. Essa rotação magnética é chamada de parede de Bloch. Nesta região da rotação emerge uma informação através da superfície. Esta informação magnética emergente da superfície será utilizada para observar a microestrutura magnética dos aços através da técnica Bitter.

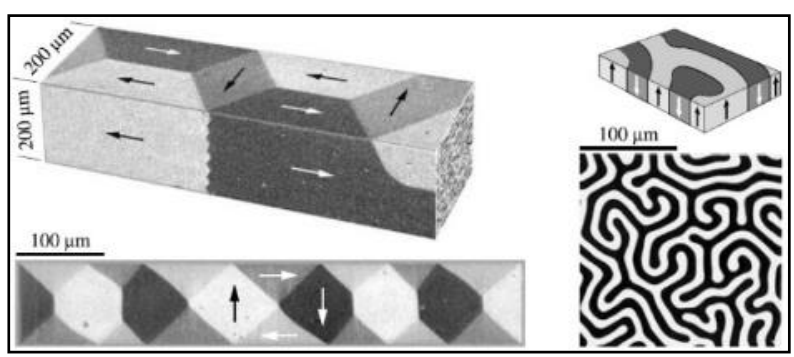

Figura 1. Ilustração das diferentes orientações dos domínios magnéticos [3].

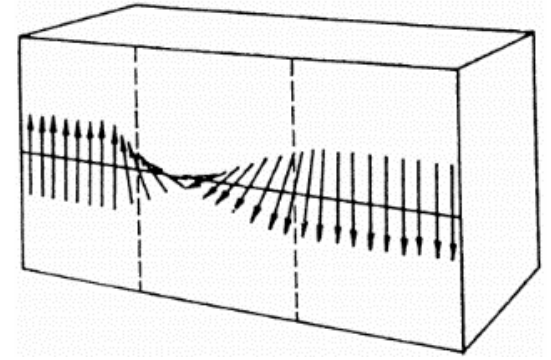

Figura 2. Representação das paredes de Bloch [3] 


\subsection{Técnica Bitter e Ferrofluido}

A técnica Bitter consiste no recobrimento de uma amostra ferromagnética com uma solução coloidal que contenha partículas ferromagnéticas. Estas partículas tenderão a se concentrar nas regiões de maior gradiente de campo magnético, ou seja, as paredes de Bloch. Com isto poderá ser observado em microscopia ótica as regiões onde os domínios magnéticos se apresentam [4].

As partículas ferromagnéticas desta solução não apenas são atraídas pelas regiões ferromagnéticas da amostra, como também influenciam a disposição dos domínios magnéticos. Esta influência se torna um problema quando desejamos observar modificações nestes domínios causadas apenas pela deformação plástica, já que as partículas ferromagnéticas podem alterar a natureza dos domínios magnéticos. Para sanar tal problema, foi usado o ferrofluido.

Ferrofluido é uma solução coloidal de partículas paramagnéticas na escala nanometrica. Este fluido reage mesmo a ínfimos campos magnéticos. As partículas paramagnéticas apenas reagem ao campo magnético proveniente das paredes de Bloch (fronteira entre os domínios) aglomerando-se nestas regiões, e não irão influenciar estes domínios, já que estas partículas não possuem um campo magnético próprio [5].

\section{MATERIAIS E MÉTODOS}

Foram analisadas três amostras laminadas de diferentes aços, os quais eram: DIN St12; DIN St37 e DIN CK45. Os aços St12, St37 e CK 45 são aços de construção ferríticos com as respectivas concentrações de carbono: $0,12 \% ; 0,17 \% ; 0,45 \%$.

Estas amostras foram cortadas utilizando-se um disco de corte 30A13 e posteriormente embutidas utilizando o meio de embutimento a frio Dermotec 35. As amostras embutidas foram preparadas através dos processos metalográficos padrões de forma manual, de modo a evitar a magnetização das amostras pelos equipamentos.

No processo metalográfico foram utilizadas as seguintes lixas em sequência: P320, P600 e P1200. Posteriormente as amostras passaram pelo processo de polimento com panos de polir DAC $3 \mu \mathrm{m}$ e NAP $1 \mu \mathrm{m}$, com respectivos líquidos com partículas de diamante $3 \mu \mathrm{m}$ e $1 \mu \mathrm{m}$, e, para o acabamento final, utilizou-se um pano de polir para OPS com o líquido de polimento MasterMet 25.

Para a observação da microestrutura convencional dos materiais estudados foi utilizado o ataque químico com nital entre 10 a 15 segundos.

Para a observação da microestrutura magnética dos materiais em questão foram utilizados os ferrofluidos da série EMG da empresa Ferrotec, são eles: EMG 308, EMG 408, EMG 508 e EMG 807 que utilizam água destilada como meio de dissolução e o EMG 911 que utiliza óleo mineral como meio de dissolução. Utilizando-se ferrofluidos à base de água, a diluição ideal encontrada foi de uma gota de ferrofluido para 160 gotas de água destilada. Quando o meio de dissolução em questão era óleo mineral, temos que a proporção ideal é uma gota de ferrofluido para 60 gotas de óleo mineral. Após aplicação da solução e respectivos tempos de secagem, as amostras foram levadas para microscopia ótica.

A fim de observar as alterações nos domínios magnéticos após a deformação plástica, o seguinte experimento foi proposto: a primeira etapa foi a observação dos domínios magnéticos em áreas específicas dos materiais. A segunda etapa foi à realização de três indentações (nas áreas supracitadas) com uma esfera de 2,5 mm 
de diâmetro do tipo Brinnel, na diagonal das amostras, com idênticas cargas $(612,9 \mathrm{~N}$ com uma distância de $7,0 \mathrm{~mm}$ entre si para evitar a zona de influência da deformação) para serem utilizadas como parâmetros de medida principal. Também foram realizadas duas indentações do tipo Vickers nas bordas das amostras para serem utilizadas como controle, de forma, a saber, a perda de material durante os processos metalográficos subsequentes.

A terceira etapa consistiu na preparação metalográfica das amostras de modo a retirar as indentações por meio das lixas e polimentos até as amostras ficarem novamente planas. Após isto foi aplicado novamente o ferrofluido onde estavam as indentações (área anteriormente observada) e notou-se a alteração nos domínios magnéticos.

\section{RESULTADOS E DISCUSSÃO}

Serão apresentados a seguir os resultados da observação da microestrutura magnética das amostras sem deformação, a correlação das microestruturas convencionais (fases e tamanhos de grão) com as microestruturas magnéticas e por fim as alterações magnéticas macro e microestruturais das amostras após deformação plástica.

\subsection{Microestruturas Magnéticas das Amostras antes da Deformação Plástica}

As partículas paramagnéticas concentram-se sobre as paredes de Bloch, desta forma a distância entre duas listras ou linhas nas imagens acima significam um domínio magnético.

$\mathrm{Na}$ Figura 3 é possível observar claramente que os domínios magnéticos apresentam-se de forma alongada e paralela. Na Figura 4 observamos que os domínios magnéticos se apresentam mais curtos e as partículas paramagnéticas concentram-se não apenas nas paredes de Bloch, mas também em regiões específicas. Posteriormente será apresentado que tais regiões são áreas onde se tem perlita. Na Figura 5 ainda podemos observar linhas paralelas que são as fronteiras dos domínios, porém com um pouco mais de dificuldade. Isto se deve ao fato de que esta amostra possui um maior teor de carbono em sua concentração, o que dificulta um pouco mais a observação dos domínios magnéticos devido à formação de perlita.

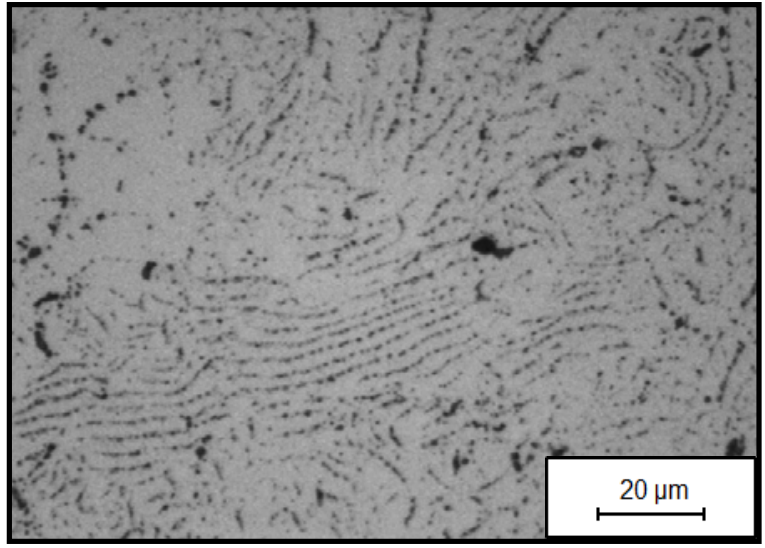

Figura 3. Domínios magnéticos na amostra St 12

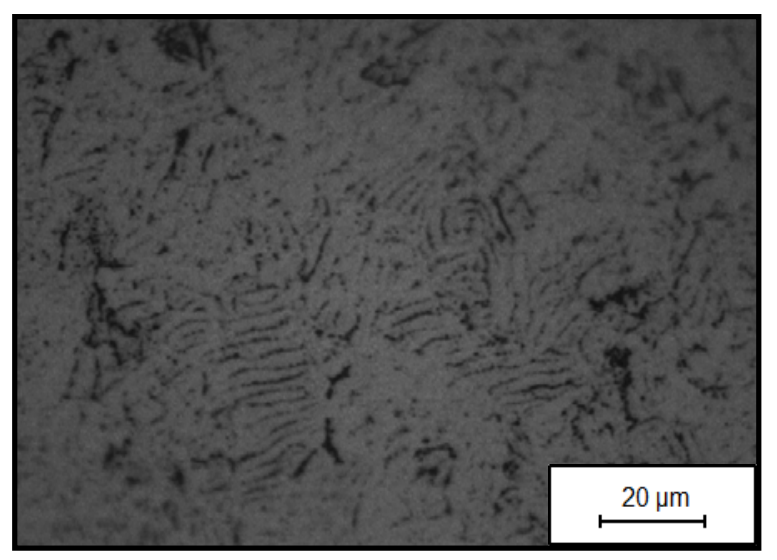

Figura 4. Domínios magnéticos na amostra St 37 


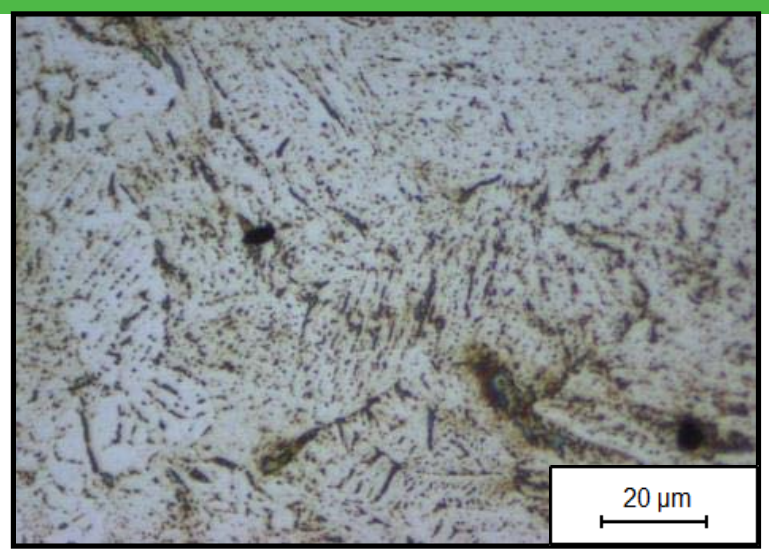

Figura 5. Domínios magnéticos na amostra CK 45.

\subsection{Correlações das Microestruturas Convencionais (Fases e Tamanhos de Grão) com as Microestruturas Magnéticas.}

Nas Figura 6 e 7 observa-se em detalhes um exemplo da amostra St37 que apresenta estrutura perlítica. Uma mesma região da amostra foi previamente marcada e ensaiada através da solução com ferrofluido. Após captura de imagens da região com ferrofluido (microestrutura magnética), a amostra foi limpa e atacada com nital. Desta forma pode-se comparar a microestrutura magnética com a microestrutura convencional.

$\mathrm{Na}$ Figura 6 pode-se observar os domínios magnéticos, porém destaca-se uma região com grande aglomeração de partículas paramagnéticas. Ao analisar a imagem 5, microestrutura convencional, observa-se que a região com grande aglomeração de partículas é, na verdade, a região onde se encontra perlita. Isto se deve ao fato do alto caráter ferromagnético da cementita, que é um constituinte da perlita [6].

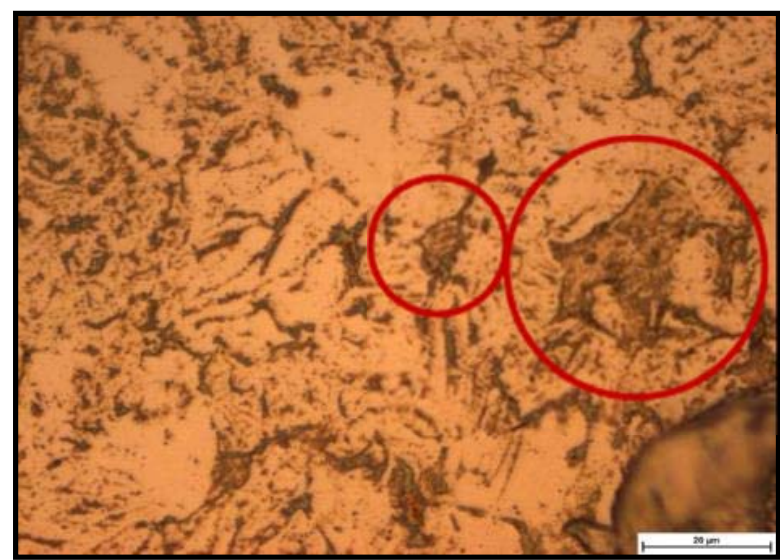

Figura 6. Microestrutura magnética (Perlita) da amostra St37.

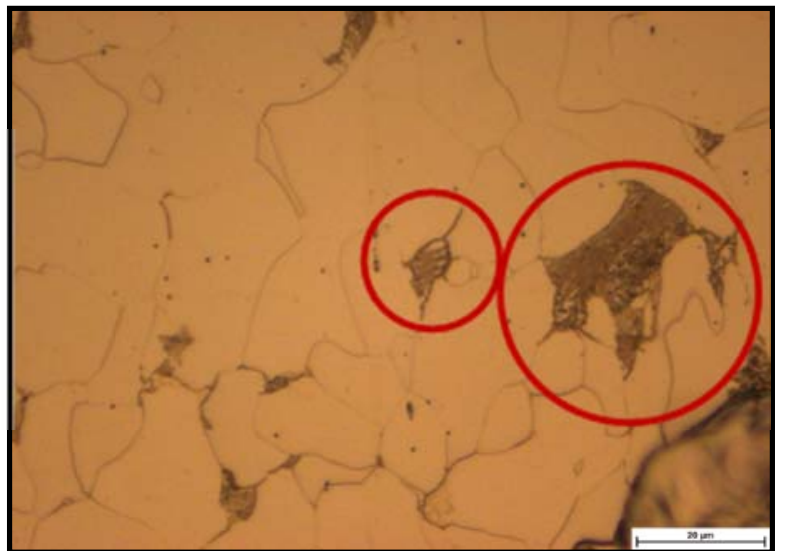

Figura 7. Microestrutura convencional (Perlita) da amostraSt37

Repetindo o mesmo procedimento para uma amostra do aço St12 tem-se mais uma correlação da microestrutura magnética com a microestrutura convencional.

$\mathrm{Na}$ Figura 8 observa-se o contraste da microestrutura magnética. Na Figura 9 foram destacados os contornos de grão da microestrutura na mesma região. A sobreposição das linhas destes contornos de grão sobre a Figura 8 nos permite observar uma correlação do contraste da microestrutura magnética com os contornos de grão. Isto ocorre porque os contornos de grão são também áreas onde 
temos informação magnética devido a interface dos domínios magnéticos de diferentes orientações.

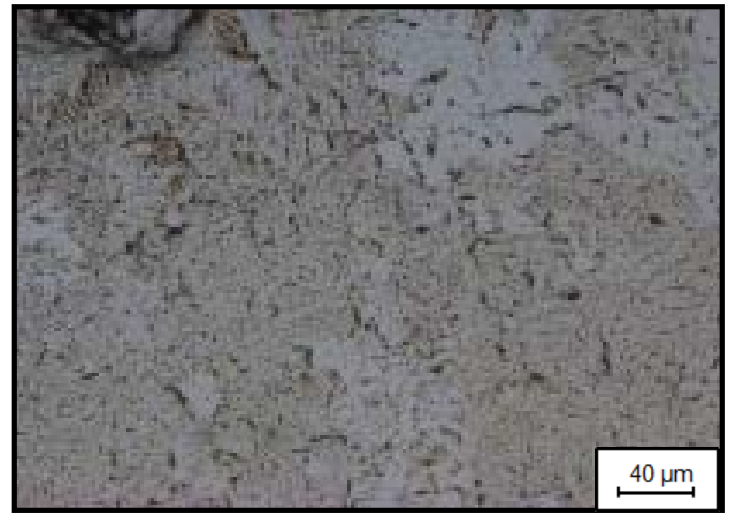

Figura 8. a) Microestrutura magnética da amostra St12.

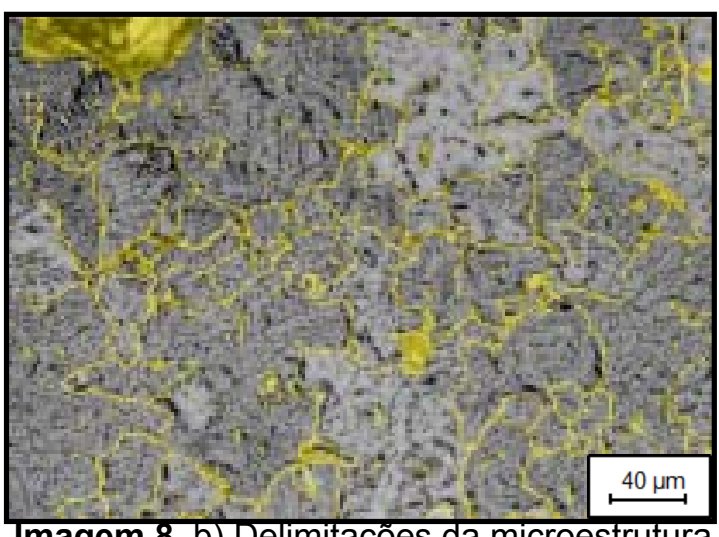

Imagem 8. b) Delimitaçóes da microestrutura magnética da amostra St12.

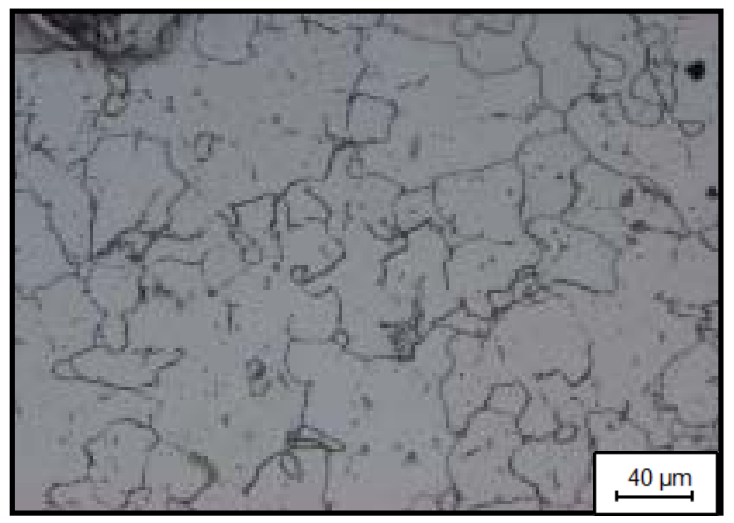

Figura 9. a) Contornos de grão da amostra St12

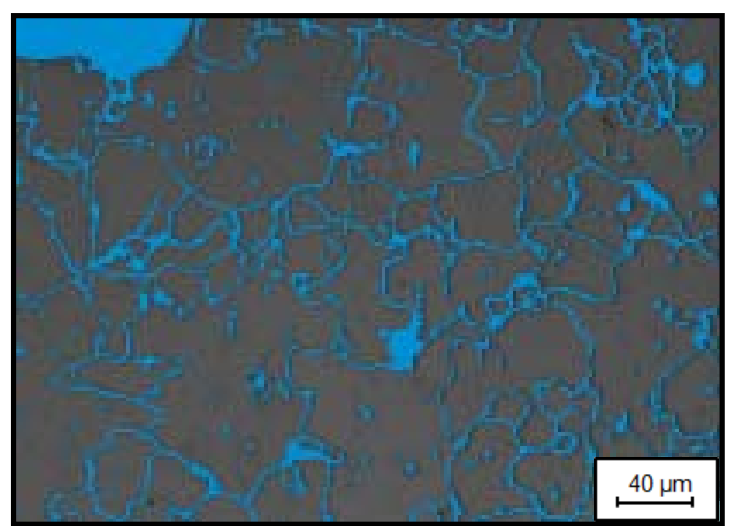

Tmagem 9. b) Sobreposição das delimitaçôes da imagem 6. b na imagem 7. A.

\subsection{Mudanças nos Domínios Magnéticos após Deformação Plástica para o Aço St37.}

Nas Figuras 10 a 12 pode-se se ver ainda em uma área macroscópica que com o auxílio do ferrofluido se observa a área onde as indentações haviam sido feitas. As partículas paramagnéticas aglomeram-se exatamente na área que foi deformada plasticamente. Isto reafirma que após deformação plástica ocorre uma alteração na intensidade de campos magnéticos da amostra.

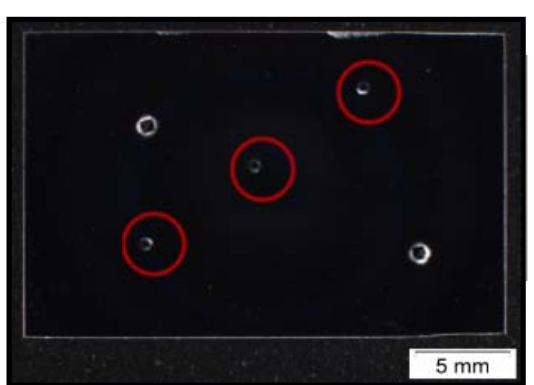

Figura 10. Amostra St $37 \mathrm{com}$ identações.

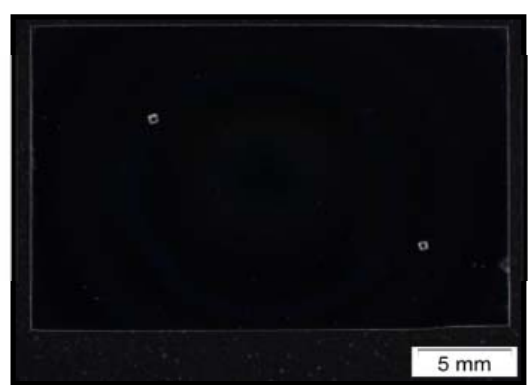

Figura 11. Amostra St 37 após as indentações serem removidas por lixamento e polimento.

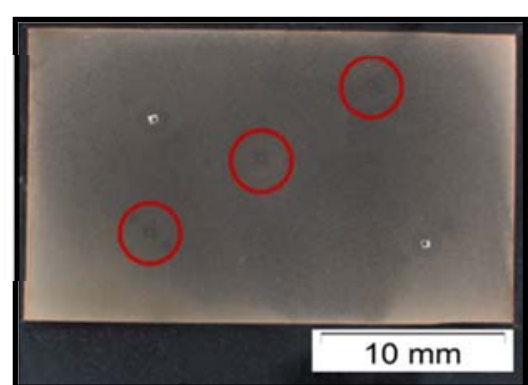

Figura 12. Áreas onde haviam as indentações são reveladas com ferrofluido. 
Ao observar as áreas destacadas na imagem 10 (com ferrofluido) em um maior aumento e compará-las com imagens feitas da microestrutura magnética da mesma amostra antes da deformação, temos que após a deformação os domínios magnéticos apresentam uma variação em seu tamanho (distância entre duas paredes de Bloch) e também modificações em sua morfologia. As Figuras 13, 15 e 17 representam as microestruturas magnéticas destas áreas antes da deformação plástica, já as Figuras 14, 16 e 18 representam as microestruturas magnéticas destas áreas após a deformação plástica.

Na Figura 13, capturada em campo escuro, pode ser observado que a distância entre duas fronteiras de domínio magnético (o tamanho de um domínio magnético) é cerca de $3,0 \mu \mathrm{m}$, enquanto na mesma região na Figura 14, após a deformação plástica, este tamanho é de $8,0 \mu \mathrm{m}$.

Na Figura 15 vê-se novamente a microestrutura magnética de um aço St 37 antes de ser deformado plasticamente. Na Figura 16 vê-se esta mesma região após deformação plástica e observa-se que a estrutura de domínios magnéticos sofre uma alteração em sua morfologia. Esta estrutura se mostra semelhante a uma espinha de peixe, onde temos aglomerações de partículas formando uma linha central e finas parede de Bloch com suaves inclinações ao redor desta linha.

Comparando as Figuras 17 e 18 vemos a formação de uma conhecida estrutura de árvore. Pode-se atrelar a alteração das propriedades magnéticas das amostras estudadas após deformação plástica com as alterações no tamanho e forma de seus domínios magnéticos.

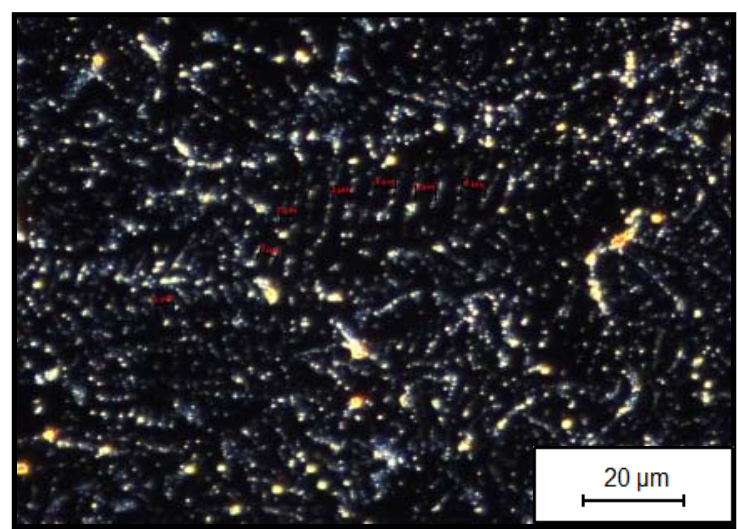

Figura 13. Microestrutura magnética St37 antes da deformação plástica. Imagem capturada em campo escuro.

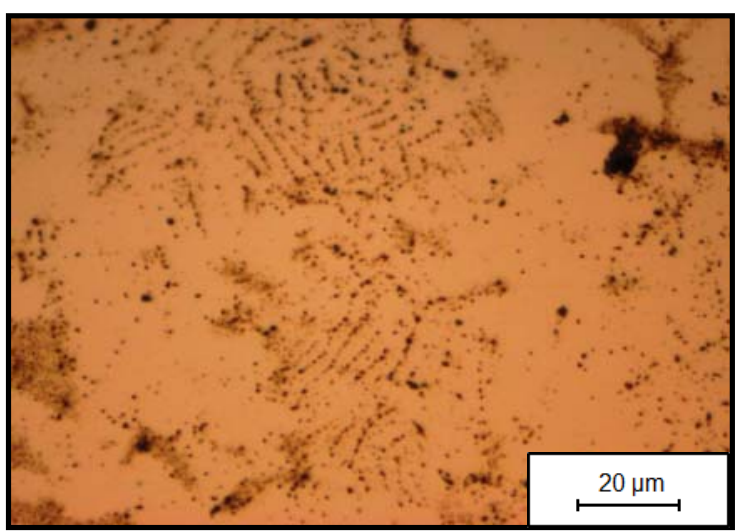

Figura 15. Microestrutura magnética St37 antes da deformação plástica.

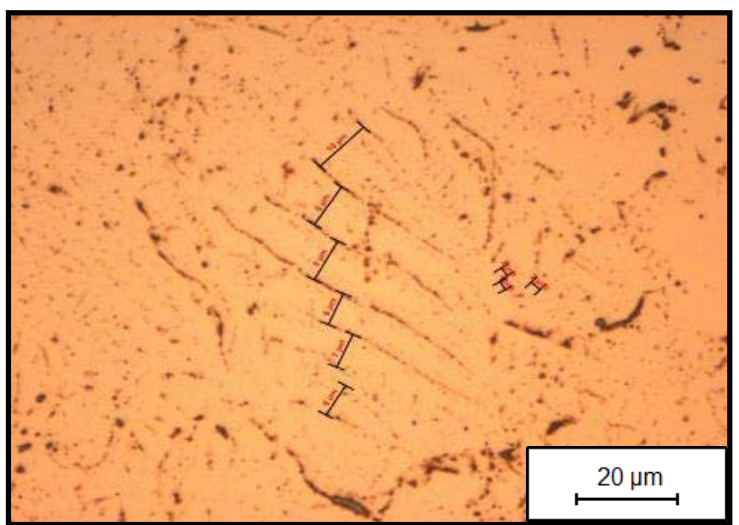

Figura 14. Microestrutura magnética St37 após deformação plástica. Imagem capturada em campo claro.

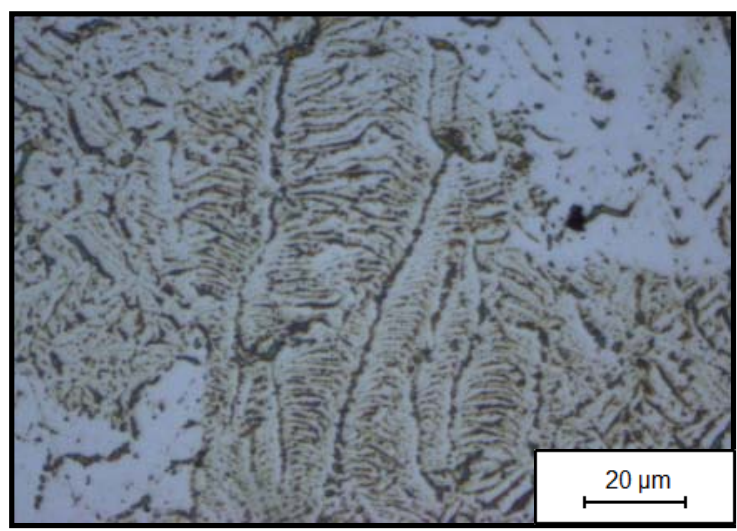

Figura 16. Microestrutura magnética St37 após deformação plástica. 


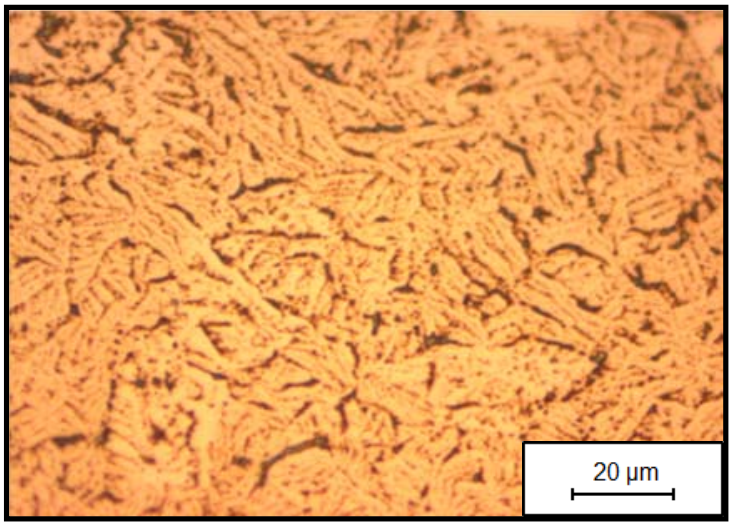

Figura 17 Imagem 15. Microestrutura magnética St37 antes da deformação plástica.

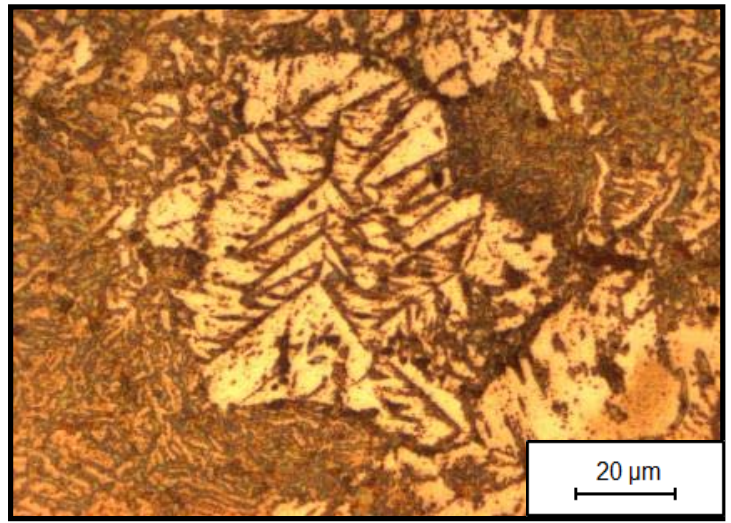

Figura 18 Imagem 14. Microestrutura magnética St37 após deformação plástica.

\section{CONCLUSÃO}

Após os resultados apresentados conclui-se que a técnica Bitter através do ferrofluido pode ser eficiente para a observação de domínios magnéticos em alguns aços ferríticos.

Foi observado que a concentração de carbono influencia na observação de tais domínios de forma que quanto maior a concentração de carbono no material maior será a dificuldade de observação, pois o carbono pode formar novas fases que possuem maior caráter ferromagnético que a matriz, por exemplo, no caso estudado da perlita.

A microestrutura magnética se correlaciona com a microestrutura convencional, uma vez que as partículas se aglomeram, por exemplo, em regiões que mostram perlita, já que um de seus constituintes, a cementita, apresenta propriedades ferromagnéticas destacáveis quando comparadas com as da matriz. Também se observa que há uma correlação entre os contornos de grão e as delimitações das regiões de domínios magnéticos.

Observou-se que nas regiões onde surgem campos magnéticos espontâneos, após a deformação plástica, tem-se uma mudança não apenas no tamanho dos domínios magnéticos, mas também em sua morfologia. Isto pode vir a ser a justificativa para tal modificação espontânea das informações magnéticas dos materiais pesquisados. Para tal são ainda necessários métodos complementares para a observação dos domínios magnéticos, por exemplo, microscopia Kerr, já que os domínios se apresentam no volume da matéria e o estudo feito até o momento é através de microscopia óptica, ou seja, bidimensional.

\section{Agradecimentos}

Lucas Kling e Silva agradece ao apoio do programa Ciência sem Fronteiras chamada 127/2012 devido ao suporte financeiro proveniente da CAPES e CNPQ e agradece também a BAM Bundesanstalt für Materialforschung und -prüfung pela estrutura e suporte oferecidos. 


\section{REFERÊNCIAS}

1 Dubov, A.A., A study of metal properties using the method of magnetic memory. Metal Science and Heat Treatment, 1997. 39(9-10): p. 401-405.

2 Nadja Sonntag. Nondestructive Detection of Mechanically Induced Magnetic Stray Fields in Steels. Junior Euromat. 2014.

3 Rudolf Schäfer e Alex Hubert. Magnetic Domains The Analysis of Magnetics Microstructures. 5ed. Dresden. Springer. 2009.

4 Alex Hubert. Bitter-Streifen und Bloch-Wände. Zeitschrift für Physik. Volume 180, Issue 1, pp 80-90. 1974

5 Russel, W.B., Saville, D.A., Schowalter, W.R., 1989, Colloidal Dispersions, Cambridge

6 S.W.J. Smith; W. White; S.G. Barker. (1911). "The Magnetic Transition Temperature of Cementite". Proc. Phys. Soc. London 